\title{
Intercultural Competence: The Status and Future of a Controversial Concept
}

\author{
Stefanie Rathje \\ University of Jena, Germany
}

The paper reviews the current state of research into the long-disputed concept of intercultural competence by evaluating its varying definitions in German debates. The superficial clarity of the concept is unmasked to reveal fundamental differences in the answers given to questions like: what is the goal of intercultural competence; is intercultural competence universal or culture-specific; in which situations is intercultural competence needed; and what understanding of culture forms the basis of intercultural competence? The requirements for an applicable understanding of intercultural competence are derived, leading to a set of suggestions for the development of the concept on the basis of a contemporary, cohesion-oriented definition of culture.

Der Artikel beschreibt den Forschungsstand zum Konzept Interkulturelle Kompetenz anhand der Darstellung und Bewertung des Spektrums unterschiedlicher Definitionsansätze in der deutschsprachigen Debatte. Auf dieser Basis werden Vorschläge für eine Weiterentwicklung des Konzepts auf der Grundlage eines kohäsionsorientierten Kulturverständnisses entwickelt.

doi: 10.2167/laic285.0

Keywords: intercultural competence, culture, intercultural management, cultural cohesion, cultural coherence

\section{Introduction}

[...] to what degree is it actually possible, for an expert from one culture to communicate with, to get through to, persons of another culture? (Gardner, 1962: 241)

When the American social psychologist Gardner posed this question about what we now commonly refer to as intercultural competence, he responded to his own inquiry with an appropriate hypothesis. Gardner introduced the concept of 'universal communicators', that is, individuals equipped with an unusual capacity for intercultural communication along with an entire repertoire of personality traits that contribute to this success: integrity, stability, extroversion, socialisation in universal values and including special intuitive and even telepathic abilities (Gardner, 1962: 248). Nearly a half a century later, academic and professional attention is still drawn to the observation that some individuals are obviously more adept in intercultural situations than others. Unlike in the earliest days of intercultural competence research - which primarily found its application in student exchange or international technical aid programmes - a more diversified field of research contexts has emerged in recent years. Increased intercultural interactions have offered many new 
social, political and economic 'trouble spots'. Migration issues, multicultural social environments, workforces that operate internationally and certainly mergers between foreign companies have all gained insights from intercultural research. The intersection of political interests with economic marketability has doubtless also contributed to the increasing intensity of the debate surrounding the concept known as 'intercultural competence'.

A variety of academic disciplines have so far laid claim to the concept and produced a number of models to describe intercultural competence and its development. Among them, one can distinguish between the so-called 'list models' and 'structural models' (Bolten, 2006). The list models can be understood as a kind of catalogue of 'separate competences' (as in Gardner's description) which might include stress-resistance or empathy. Structural models, on the other hand, treat intercultural competence as a kind of procedural system in which individual abilities are assigned to specific categories. One often-cited model, for example, incorporates affective, cognitive and behavioural dimensions into a larger framework of intercultural competence (Gertsen, 1990). Besides these two individual-oriented approaches, there are additional situational and interactionistic models that emphasise the context in which the interaction takes place or rather the interdependencies between participants involved in a particular intercultural communication episode (Thomas, 2003a: 142f). The dizzying amount of material can be explained to a great extent by the lack of any unity in the definition of the term 'intercultural competence' itself. Differing understandings of the most fundamental nature of intercultural competence and hence its appropriate application necessarily lead to differing perspectives on the discrete competences of which it may be composed or, indeed, whether it can be learnt.

\section{The Current Debate in the German-speaking World}

The analysis focuses on the academic debate in the German-speaking world. The starting point is the discussion generated by the 2003 overview of intercultural competence by the psychologist Alexander Thomas. Thomas (2003a) presents an educational model of intercultural competence that elicited extensive commentary from no fewer than 30 scholars from a variety of related disciplines. Even a cursory assessment of the reaction to Thomas' work demonstrates that the contemporary discussion surrounding intercultural competence is characterised by heterogeneity and even confrontation. Precisely for this reason, few of the comments on Thomas' article engage directly with the educational model itself, but rather focus attention on broader, inter-related and fundamental issues regarding intercultural competence, namely its:

- Goal: what is intercultural competence good for?

- Scope: is intercultural competence universal or culture-specific?

- Application: when is intercultural competence required?

- Foundation: what understanding of culture informs intercultural competence? 
The following analysis seeks to present the state of contemporary research into the concept of intercultural competence by evaluating the spectrum of its various definitions. Based on this analysis, a proposal for the further development of the definition of intercultural competence is offered. This attempt is guided by the overall goal of increasing the consistency of the concept of intercultural competence, while preserving its practical applicability.

\section{Goal of intercultural competence}

Opinions regarding the purpose of intercultural competence range from economically oriented applications that emphasise efficiency to more academic or education-based perspectives that emphasise human development.

Approaches that seek to exploit intercultural competence as a means to more efficient interaction typically define the term with an emphasis on productivity in intercultural interactions. Proponents of this perspective therefore see intercultural competence as an instrument and a means to success. Thomas (2003a) shares this perspective; he defines intercultural competence as the ability 'to (help) shape the process of intercultural interaction in a way that avoids or contextualises misunderstandings, while creating opportunities for cooperative problem solving in a way that is acceptable and productive for all involved' (Thomas, 2003a: 141). ${ }^{1}$ Schönhuth (2005: 102) summarises similar definitions of intercultural competence as the ability 'within an intercultural context to establish contact in an appropriate way and to establish conditions that are acceptable for the free expression and effective exchange of all involved'. Consequently, 'a level of cooperation is achieved that is agreeable to all participants .... allowing the existing diversity ... to be exploited for the achievement of common goals' (Schönhuth, 2005: 103). Although the above definitions leave concepts like 'productivity', 'effectiveness' and 'optimal goal attainment' open to interpretation, they share the notion that intercultural competence should lead to the successful achievement of the participants' goal, be it a signed business contract, a political agreement or a meal ordered in a restaurant.

\section{Efficiency and intercultural competence}

The efficiency model is subject to a number of accusations that claim it is vulnerable to manipulative behaviour. Critics point out that there is indeed a danger of instrumentalising the concept in order to gain certain strategic advantages, for example in negotiations characterised by power differences (Aries, 2003: 153; Frindte, 2003: 171; Straub, 2003: 207). The accusations reveal other difficulties as well: the efficiency model implies the assumption that intercultural competence itself presupposes the achievement of certain goals in an intercultural environment. In response to this, Herzog points out that there appears to be a lack of distinction between 'competence' and 'performance' (Herzog, 2003: 179).

It is clear, then, that goal-oriented definitions that privilege criteria of efficiency place excessive demands on the concept of intercultural competence. Following this model, any potential result arising from intercultural interac- 
tion - including negative results - would be attributable to intercultural competence. Additionally, the model ignores the myriad external conditions that can also influence the eventual 'success' of the interaction. Such variables include the strategic target of the interaction itself, the practicality of the cooperation or the relative power structure of the participant groups. To prevent intercultural competence from becoming a concept understood simply as a 'key to success', the definition of the term needs to be refined and narrowed, divorcing 'intercultural competence' from 'successful interaction'.

\section{Human development and intercultural competence}

The opposing viewpoint to the efficiency model of intercultural competence is one that emphasises the importance of effective human interaction in the expectation that successful intercultural competence will manifest itself in the participants as a kind of palpable personal development. Wierlacher, for example, defines intercultural competence as a capacity whose success is best measured in individual growth. This act of personal development is itself described as an 'establishment of discrete commonalities upon a certain plane of significance' (Wierlacher, 2003: 216).

As the goals of the intercultural interaction (whether personal, economic or of another type) are not specified in this description, the approach is vulnerable to criticism for being too idealistic (Thomas, 2003b: 223). In order, therefore, for the concept to be of any pragmatic use, its definition must explicitly consider the situational objectives of those involved.

\section{Scope of intercultural competence}

An analysis of opinions regarding the general scope of a concept of intercultural competence naturally reveals a wide variety of interpretations. These range from a narrow understanding of a competence which is applicable only to a specific culture, while other approaches extend the term to include a full range of social and practical competences.

\section{Culture-specific competence}

At one extreme, one finds proponents of an approach who claim that intercultural competence is grounded in the experience and knowledge of one or more foreign cultures. Herzog, for example, poses the problem, 'how exactly a "bi-cultural competence" can be understood as an expression of "intercultural competence", or even how one idea can follow from the other'. He concludes that generalised (i.e. non-culture-specific) intercultural competence 'is just as hollow a concept' as non-specific foreign language competence (Herzog, 2003: 179). Approaches that equate intercultural competence with a specific cultural competence, however, immediately render the term obsolete and enforce narrow categories of competence such as (at the level of national cultures, for example) 'USA competence' or 'Switzerland competence'. Such an understanding of intercultural competence contradicts the observation that some individuals with a certain level of experience in foreign environments are more adept at navigating through other unfamiliar situations. The existence of such a condition is indeed the reason for the development of 
the concept of intercultural competence and remains an important justification for the term. The acceptance of a culture-specific understanding of intercultural competence would therefore do little to promote the validity of the concept itself.

\section{Generalised intercultural competence}

An understanding of intercultural competence as a universal competence, that is, one that is not bound to a specific culture or combination of cultures, is a view that is most often shared by those who see intercultural competence as a means of personal development. Wierlacher, for example, defines intercultural competence as a generalised cultural competence that 'seeks to promote and facilitate a new system of orientation among people of different cultures' (Wierlacher, 2003: 216). Other authors choose to emphasise the ability to handle unfamiliar situations (Mecheril, 2003: 198) or to engage in 'reasonable interaction' in foreign contexts (Loenhoff, 2003: 193). While these definitions of intercultural competence do extend the scope of the concept and preserve the broad utility which gives the idea its value, a concrete definition is still lacking. Phrases such as 'reasonable interaction' and 'promote and facilitate' are frequently used by proponents of generalised intercultural competence but their meanings remain frustratingly unclear.

\section{General social competence}

Interpretations of intercultural competence that emphasise the applicability of the concept tend to divide the overall competence into discrete and separate fields of competence. These approaches sometimes gather the necessary discrete competences into list models or structures that, as a whole, attempt to describe intercultural competence. An analysis of such models reveals quite clearly that with the exception of certain foreign-language knowledge or specific cultural awareness, what remains of the 'separate competences' strongly resembles a generalised social competence (Linck, 2003: 191; Nový, 2003: 206). Indeed, it is difficult to formulate arguments against the understanding of intercultural competence as something approaching a generalised social competence. As intercultural interaction is itself a form of social interaction, it is clear that appropriate intercultural communication would require social competence as well. A definition of intercultural competence that seeks to equate it with social competence, however, ignores the 'exceptional difficulty' (Hansen, 2000: 318f) inherent in the examination of intercultural interaction that is frequently experienced by participants in such communication contexts.

\section{Transfer of generalised 'action competence'}

Additionally, one also finds approaches that place intercultural competence in a more practical framework of 'action competence' and include social competence only as a single discrete category among others. These separate fields of competence may include such categories as individual competence, expertise and strategic competence with social competence included among the other separate fields (Bolten, 2003: 157). The argument here is that an actor 
in an intercultural environment who lacks expertise in the relevant field will be unable to interact effectively in such an environment despite the fact that he may indeed possess abilities necessary to deal with unfamiliar situations. Once again, we see the difficulty in defining intercultural competence as a key to communicative efficiency. When the definition of intercultural competence is reduced to a means to reach certain practical goals, logically, the concept must transfer and incorporate general action competence, as success of the intercultural interaction would necessarily be dependent on all possible action competences.

An understanding of intercultural competence that requires supplemental abilities such as mathematical skills or computer programming in addition to a wide variety of social competences is impractical. Instead of attempting to integrate all possible action competences into a single definition of intercultural competence, one might instead define intercultural competence itself as a competence necessary if participants in an intercultural context wish to make the most of their potential action competences.

\section{Application of Intercultural Competence Inter-national interaction}

The debate regarding the application of the term 'intercultural competence' is characterised by two extreme positions that identify either 'inter-national' or 'inter-collective' interaction. Proponents of an 'inter-national' interpretation of intercultural competence generally define the context for intercultural interaction as one involving individuals from different national cultures. This approach represents the 'classical' form of the study of intercultural competence in which cultural disturbances are typically traced back to the participants' country of origin, and therefore sees international communication as a form of true interculturality. Thomas employs national-culture examples when describing encounters between German and Chinese scientists as well as American managers interacting with Greek workers. The reduction of the difficulties inherent in intercultural competence to a category of national culture certainly has pragmatic advantages (Krotz, 2003: 183) as it is supported by the subjective feelings of alienation and the high probability of misunderstanding that are frequently associated with encounters between members of different national cultures. The approach has, however, become a target of harsh criticism especially from sociologists and educators who argue that it is oversimplified (Auernheimer, 2003: 154) or accuse its proponents of encouraging intra-national homogeneity (Allolio-Näcke, 2003: 151).

This somewhat polemical dispute betrays a problematic lack of clarity within the inter-national approach. If intercultural competence is primarily a description relevant to individuals from different countries, the term then excludes intercultural problems that may exist within national boundaries. The approach is therefore unable to distinguish between 'inter-national' intercultural situations and 'intra-national' ones. 


\section{Inter-collective interaction}

A number of authors point to the existence of 'foreign' experiences, subcultures, organisational cultures and various cultural strata within a presumably uniform national culture (Frindte, 2003: 169; Linck, 2003: 191; Straub, 2003: 209). They choose, therefore, to abandon the terminology of national cultures in favour of an inter-collective model that describes the interaction between individual members of specific collectives with their own distinctive culture. In this way, the inter-national approach becomes simply a single, if special, form of inter-collective communication. It seems reasonable, therefore, to apply a broader 'life-world' understanding of culture to the term 'intercultural competence' and to treat it as an 'inter-collective' model rather than limiting it to a single 'inter-national' application. This decision, however, on a 'micro-level' leads to the opposite problem of how to draw a line between a 'normal' and an 'intercultural' interaction as basically any human encounter would have to be defined as intercultural. Consequently, it becomes advantageous to consider the personal interpretations of the participants in a definition and to limit intercultural communication to situations in which the participants 'attribute the characteristics of this process as well as the problems and conflicts that arise to cultural differences' (Loenhoff, 2003: 193).

\section{Cultural foundation}

The final source of dispute involves the very understanding of the term 'culture' when used in the context of intercultural competence. Numerous educationalists and sociologists vehemently criticise Thomas' initial definition of culture, accusing him of cultural determinism (Auernheimer, 2003: 15). Some critics cite 'mystification', 'one-dimensionality' or 'universalism' as flaws in Thomas' thesis, while still others allege a political rejection of cultural transfer (Allolio-Näcke, 2003: 150f). Although these controversial positions appear to be inadequately supported, the sheer volume of criticism that deals specifically with the definition of culture indicates that the debate continues to resonate in the field of intercultural studies.

\section{Coherence}

The coherence-oriented approach to culture represents a rather traditional understanding in that it describes culture as something unifying which produces common characteristics shared by a significant number of the members of that culture. Although this approach does not deny variations or even contradictions within the culture in question, the dominant idea is one that culture is itself the homogeneous (coherent) nature expressed in a group of human beings (Rathje, 2004: 52ff). Thomas clearly aligns himself with this school when he writes that culture is a 'universal and quite typical orientation system for a society, organization or group' (Thomas, 2003a: 52ff). In his investigation of 'orientation systems', he identifies the so-called 'cultural standards' which 'the majority of the members of a certain culture recognise within themselves and others as normal, self-evident, typical and binding' (Thomas, 1996: 112). While a coherence-oriented definition of culture seems convenient, as it confirms the subjective perception of cultural differences 
between nations, the idea of the individual being the member of a single coherent culture in a complex age of globalisation and social differentiation is one that is obviously untenable (cf. Feldtkeller, 2003: 165). What is required is therefore a definition of culture that explicitly addresses apparent cultural contradictions and integrates that understanding into a model of intercultural competence.

\section{Differentiation}

Unlike the coherence-oriented definition of culture, other approaches choose to accentuate differentiation within a specific (possibly national) culture and embrace the fundamental contradictions present within them. Some of the topics frequently addressed include the critique of cultural homogeneity (Mae, 2003: 194; Mall, 2003: 196), the existence of internal inconsistencies and hybridity within cultures (Allolio-Näcke, 2003: 151; Geiger, 2003: 173), which can be traced back to the individual himself (Straub, 2003: 208), as well as the character of culture as a process (Auernheimer, 2003: 155).

Although these expressions of differentiation cannot be dismissed out of hand, there are still no satisfactory explanations for the apparent cohesion of cultures which is critical when dealing with a concept like intercultural competence. For this reason, Geiger warns, 'we should not underestimate the tenacity of traditions, nor the resistance of collective ... national mentalities' (Geiger, 2003: 173). Fischer poses but does not answer the paradigmatic question: 'What constitutes unity within variety? What holds a society that is made up of divergent and sometimes contrary cultural systems together?' (Fischer, 2003: 168). It becomes clear that a definition of culture that is suitable for the examination of intercultural competence has to take into account the internal differentiation of culture but also cannot ignore its apparent cohesion.

\section{Further Development of the Concept}

As a basis for further considerations, an effort should be made to formulate an acceptable definition of culture that both allows for differentiation and offers a plausible explanation for the cohesion of culture despite internal inconsistency. One such cultural model that fulfills the above criteria has been proposed by Hansen (2000). According to Hansen, cultures simply exist within human collectives. The term 'collective' includes all kinds of groups composed of individuals from football clubs to corporate organisations to nation-states. This approach differs from the narrow 'inter-national' understanding of culture and its emphasis on intercultural competence as a national phenomenon. Instead, Hansen's model allows for multiple levels of cultural involvement that can overlap or even contradict one another. The core of the approach represents a general diagnosis of differentiation within cultures (Hansen, 2000: 182) already referred to by many of the respondents to Thomas' article. Cultural differences are understood as a necessary element in the creation of the individual: culture provides the range of differing and even contradicting possibilities, analogous to the substances in a chemistry lab that achieve their 
full dynamic potential when mixed together. It is within the individual himself that a culture finds its differentiated expression (Hansen, 2000: 185). The range of possibilities within a culture is, however, finite and will necessarily differ from culture to culture, so that despite the intra-cultural variety, the individual's unique traits and characteristics can nevertheless observably refer to his cultural membership.

The term 'multicollectivity' is a useful one in understanding the seeming contradiction between individuality and the apparent integrity of large and complex collectives. Although membership in certain groups automatically leads to segregation from others, the fact that individuals are part of multiple collectives at the same time mitigates differences while fostering a networklike stability. Considering the centrifugal forces of cultural differences, it is then rather the establishment of normality than generally agreed-upon norms or values that gives cultures their cohesion. For a culture's 'most essential criterion and its most effective and profound achievement is to define normality. And this normality is as restrictive and as binding in its own way as are social and political structures' (Hansen, 2000: 232).

The obvious cohesion of cultures is not the result of their coherence, therefore, but rather their familiarity and the 'normality' of their internal differentiation. 'We are aware ... [of the divergent] perspectives and when we hear them, we know we're at home' (Hansen, 2000: 232). A German, despite his own political convictions, is quite able to distinguish and navigate German political programmes and German party representatives in times of an election, for example. He is aware of the differences in his own culture and by extension would find it rather difficult to decipher an analogous election poster in Thailand, for example.

Figure 1 compares this cohesion-based concept of culture with the traditional coherence-oriented view of culture.

The achievement of the model lies in its plausible explanation for the integrity of cultures due to the recognition of difference and not to some form of internal coherence. There is empirical evidence through the examination of corporate behaviour indicating that the integrity of corporate cultures comes, in fact, from the creation of normality and the embracing of differences rather than the imposition of homogeneity: a recent study of 13 Thai daughter companies of German multinationals shows that those companies with a cohesive corporate culture, as indicated for example by a low level of employee fluctuation, not only tolerate but actively encourage differing cultural behaviour, for example German managers that initiate and seriously participate together with their Thai employees in sacrificial ceremonies for the ghosts haunting a chemical plant (cf. Rathje, 2004).

If indeed cultures are stable not because of internal consistency but because of the recognition of differentiation, then 'interculturality' will be characterised by uncertainty or perhaps disorientation with the specific form of differentiation encountered. Intercultural interaction must then be viewed as interaction between individuals from different collectives who, due to incongruous 'spectra of difference', experience disorientation and foreignness. Accordingly, intercultural competence should be understood as the ability to bring about the missing normality and therefore create cohesion in the situation. 


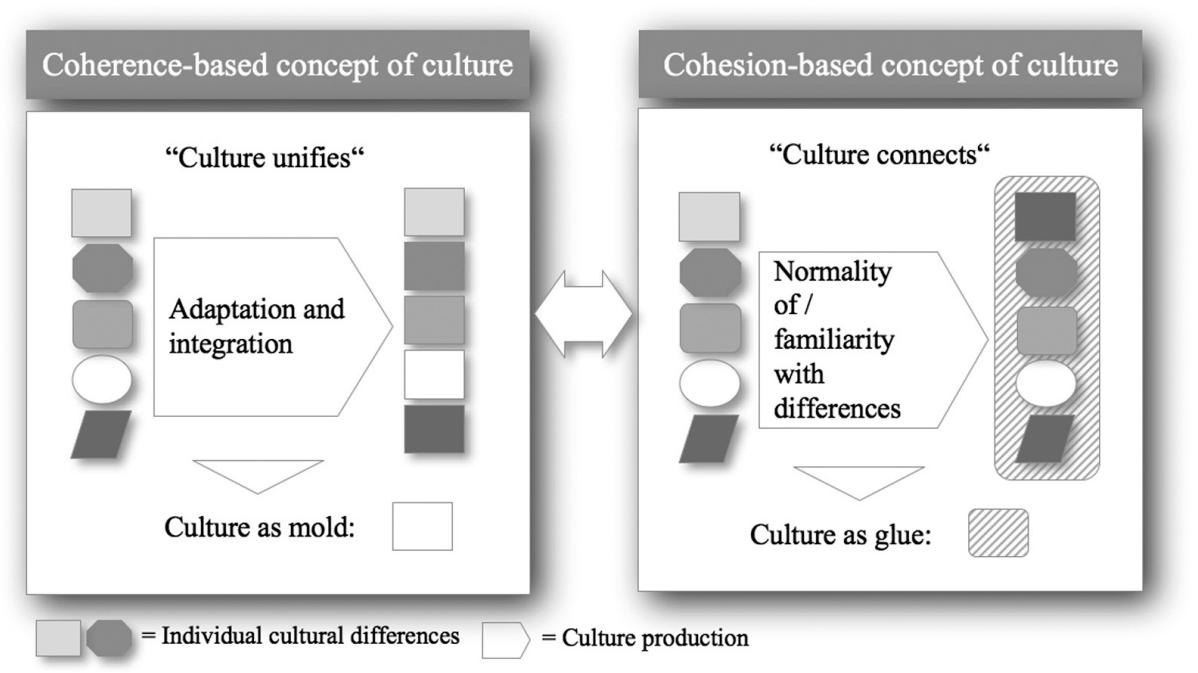

Figure 1 Coherence-based versus cohesion-based concept of culture

Intercultural competence in this sense requires that the unknown differences be made known. Further, when one applies the proposed definition of culture to this approach, it becomes clear that what is proposed here is indeed nothing less than the generation of culture. Intercultural competence must therefore be seen as the ability to transform a fleeting 'interculture' characterised by uncertainty into an actual 'culture' in which cohesion is established via normality. This interpretation of intercultural competence has an advantage in that cohesive phenomena present in intercultural communication do not require something 'third' (Wierlacher, 2003: 216) to explain them. If culture is consistently understood as a characteristic of all forms of collectives, it also applies to the cohesion between individuals from different cultures that are able to create familiarity between them, adding another collective to their individual set of group memberships (see Figure 2).

These proposals lead one to agree with Wierlacher (2003: 216) when he says that intercultural competence is a 'creative ability that seeks to promote and facilitate a new system of orientation among people of different cultures'. The result of intercultural competence, however, is not 'interculture' as a nebulous middle point, serving at the same time as the agent and result of the interaction. Instead, the outcome of intercultural competence is itself culture. Empirical evidence reveals that in international corporate settings, for example, so-called 'intercultural' synergies do not owe their effectiveness to a resulting 'interculture', but rather to cohesion that arises as a by-product of culture production (Rathje, 2004: 301f).

Intercultural competence is best characterised therefore, by the transformation of intercultural interaction into culture itself. Depending on the type of interaction, the normality and familiarity created in this process forms the basis for future communication, cooperation or coexistence. 


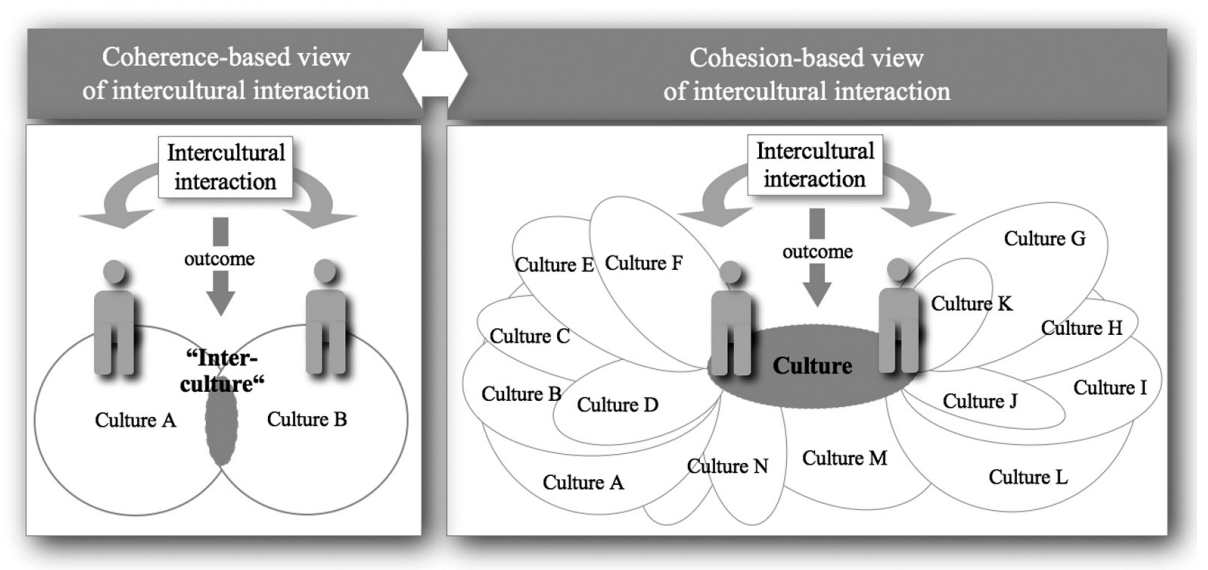

Figure 2 Coherence-based versus cohesion-based view of intercultural interaction

Such a definition of intercultural competence makes no claims about success or failure in terms of the pre-set goals as they are instead dependent on multiple external conditions such as expertise, strategic competence, situational or power factors. It prevents, however, the term from either being overestimated as a guarantee of success or dismissed as an instrument of manipulation.

In conclusion, the following tentative definition of intercultural competence is offered for reflection:

Given that ...

Foundation: culture is understood as existing within human groups, characterised by cohesion that is due to familiarity with inherent differences between them

then ...

Scope: intercultural competence can be defined as a culturegeneric skill

which is ...

Application: required in interactions between individuals from different human groups who are experiencing foreignness as a consequence of their mutual ignorance of the spectra of differences between them

Goal: $\quad$ producing culture by creating familiarity and thus cohesion amongst the individuals involved, allowing them to pursue their interactional goals. 


\section{Acknowledgement}

The author wishes to thank James McDonald (University of Jena) for his translation support.

\section{Correspondence}

Any correspondence should be directed to Stefanie Rathje, University of Jena, Institute for Intercultural Business Communication, Ernst-Abbe-Platz 8, D-07743, Jena, Germany (stefanie.rathje@uni-jena.de).

\section{Note}

1. All translations of German citations are by the present author.

\section{References}

Allolio-Näcke, L., Kalscheuer, B. and Shimada, S. (2003) Ein Lehrstück klassischen Kulturvergleichs. Erwägen, Wissen, Ethik 14 (1), 150-152.

Aries, W.D.A. (2003) Dialog und interkulturelle Kompetenz: 'Begegnung' versus 'Sozialtechnik'. Erwägen, Wissen, Ethik 14 (1), 153-154.

Auernheimer, G. (2003) Sensibilität für Kulturdifferenz genügt nicht! Erwägen, Wissen, Ethik 14 (1), 154-156.

Bolten, J. (2003) Grenzen der Ganzheitlichkeit: Konzeptionelle und bildungsorganisatorische Überlegungen zum Thema 'Interkulturelle Kompetenz'. Erwägen, Wissen, Ethik 14 (1), 156-158.

Bolten, J. (2006) Interkulturelle Kompetenz. In L.R. Tsuasman (ed.) Das große Lexikon Medien und Kommunikation (pp. 163-166). Würzburg: Ergon.

Feldtkeller, A. (2003) Dekonstruktion der eigenen Voraussetzungen: Ein Lernerfolg in interkultureller Kompetenz. Erwägen, Wissen, Ethik 14 (1), 163-165.

Fischer, V. (2003) Hinterfragung des Kulturbegriffs von Alexander Thomas. Erwägen, Wissen, Ethik 14 (1), 167-169.

Frindte, W. (2003) Die Praxis muss für sich selbst sprechen: Interkulturelle Kommunikation als komplexes Management. Erwägen, Wissen, Ethik 14 (1), 169-171.

Gardner, G.H. (1962) Cross-cultural communication. Journal of Social Psychology 58, $241-256$.

Geiger, K.F. (2003) Identitätshermeneutik: Ein verläßlicher Ratgeber? Erwägen, Wissen, Ethik 14 (1), 172-174.

Gertsen, M.C. (1990) Intercultural competence and expatriates. The International Journal of Human Resource Management 1 (3), 341-362.

Hansen, K.P. (2000) Kultur und Kulturwissenschaft. Paderborn: UTB.

Herzog, W. (2003) Im Nebel des Ungefähren: Wenig Plausibilität für eine neue Kompetenz. Erwägen, Wissen, Ethik 14 (1), 178-180.

Krotz, S. (2003) Symbolwelten und Machtstrukturen: Zwei sich ergänzende Aspekte für die Analyse von Interkulturalität. Erwägen, Wissen, Ethik 14 (1), 183-185.

Linck, G. (2003) Auf Katzenpfoten gehen und das qi miteinander tauschen: Überlegungen einer China-Wissenschaftlerin zur transkulturellen Kommunikation und Kompetenz. Erwägen, Wissen, Ethik 14 (1), 189-192.

Loenhoff, J. (2003) Interkulturelle Kompetenz zwischen Person und System. Erwägen, Wissen, Ethik 14 (1), 192-194.

Mae, M. (2003) Transkulturalität und interkulturelle Kompetenz. Erwägen, Wissen, Ethik 14 (1), 194-196.

Mall, R.A. (2003) Interkulturelle Kompetenz jenseits bloßer 'political correctness'. Erwägen, Wissen, Ethik 14 (1), 196-198.

Mecheril, P. (2003) Behauptete Normalität: Vereinfachung als Modus der Thematisierung von Interkulturalität. Erwägen, Wissen, Ethik 14 (1), 198-201.

Nový, I. (2003) Interkulturelle Kompetenz: Zu viel Theorie? Erwägen, Wissen, Ethik 14 (1), 206-207. 
Rathje, S. (2004) Unternehmenskultur als Interkultur: Entwicklung und Gestaltung interkultureller Unternehmenskultur am Beispiel deutscher Unternehmen in Thailand. Sternenfels: Wissenschaft \& Praxis.

Schönhuth, M. (2005) Glossar Kultur und Entwicklung: Ein Vademecum durch den Kulturdschungel. Trier: Trierer Materialien zur Ethnologie.

Straub, J. (2003) Interkulturelle Kompetenz und transitorische Identität in Übersetzungskulturen: Zu Alexander Thomas' psychologischer Bestimmung einer 'Schlüsselqualifikation'. Erwägen, Wissen, Ethik 14 (1), 207-210.

Thomas, A. (1996) Analyse der Handlungswirksamkeit von Kulturstandards. In A. Thomas (ed.) Psychologie interkulturellen Handelns (pp. 107-135). Göttingen: Hogrefe.

Thomas, A. (2003a) Interkulturelle Kompetenz: Grundlagen, Probleme und Konzepte. Erwägen, Wissen, Ethik 14 (1), 137-221.

Thomas, A. (2003b) Von der Komplexität interkultureller Erfahrungen und der Kompetenz, mit ihr umzugehen. Erwägen, Wissen, Ethik 14 (1), 221-228.

Wierlacher, A. (2003) Das tragfähige Zwischen. Erwägen, Wissen, Ethik 14 (1), 215-217. 